\title{
A Compact Triple Band Antenna for a Wireless USB Dongle
}

\author{
Seung Hyun Lee $\cdot$ Young-Je Sung
}

\begin{abstract}
A compact monopole antenna possessing triple resonance $\left(f_{1}, f_{2}, f_{3}\right)$ characteristics for (USB) dongle applications is presented. The resonance characteristic $f_{1}$ is determined by the overall length of the antenna. The monopole antenna acts as the main radiator for $f_{3}$ as well as the coupling feeding structure for the parasitic resonators in $f_{1}, f_{2}$. The resonance characteristic $f_{2}$ is achieved by a combination of the capacitance formed by the coupling between the top and bottom parasitic substrate resonators and the inductance generated by a via bridging the two parasitic resonators.

Key words: Monopole Antenna, (USB) Dongle Application.
\end{abstract}

\section{Introduction}

Because of the rapid development of wireless communication technology, recent research has focused on compact multiband antennas. Among these structures, multiband antennas for USB dongles are of particular interest because they are portable and enable the easy exchange of information based on a simple plug and play interface. Accordingly, several triple band antennas for USB dongle applications have been studied [1] [4]. In [1] and [2], the triple band is formed by a coupling between a monopole antenna and a parasitic resonator positioned on the bottom of the substrate. In [3], in order to cover the $2.4 \mathrm{GHz}$ band, an inverted-F antenna is used; its ground uses two slots, one for the $3.5 \mathrm{GHz}$ band and the other for the $5.5 \mathrm{GHz}$ band. In [4], a structure that has various current paths obtains different resonances through two strips added to a rectangular radiating element fed asymmetrically by a trapezoidal ground plane. However, the size of these structures is not suitable for wireless USB dongle applications.

This paper presents a triple band monopole antenna for wireless USB dongle applications. The authors have previously presented a dual-band antenna resonating at 2.4/5.2/5.8 GHz for wireless USB dongle applications [5]. The design of the proposed antenna is based on the structure outlined in [5]. A parasitic resonator in the bottom of the substrate is added to the proposed antenna and is connected to the top parasitic resonator by a via, which enables the $3.5 \mathrm{GHz}$ band for WiMAX service to be added to our previous dual-band $\left(f_{1}, f_{3}\right)$ antenna. In addition, because the top parasitic resonator is folded into a P-shape, the size of the proposed antenna is reduced by $50 \%$ compared to the monopole antenna found in [5].

\section{II . Antenna Geometry}

As Fig. 1(a) shows, the proposed antenna is composed of a monopole antenna and a parasitic radiator. The monopole is bent down to the substrate with the aim of reducing the space occupied by the antenna and effectively controlling the coupling to the parasitic radiator. In addition, the top parasitic resonator is folded into a P-shape. In order to obtain $3.5 \mathrm{GHz}$ resonance, a parasitic resonator is added to the bottom of the substrate and is connected to the top parasitic resonator by a via, unlike the structure found in [5]. Figs. 1(b) and (c) show top and bottom views of the antenna, respectively. The radiator, which is fabricated on a FR4 substrate with a thickness of $0.8 \mathrm{~mm}$ and a permittivity of 4.4, is designed as a non-GND that is equivalent to $20 \mathrm{~mm} \times 10 \mathrm{~mm}$ for efficient radiation; the antenna occupies an area equal to $10 \mathrm{~mm} \times 10 \mathrm{~mm}$. The antenna is fed through a $50 \Omega$ coaxial cable. The width of all the antenna lines except for $W_{1}$ is set at $0.9 \mathrm{~mm}$ in order to simplify the design. The distance between the monopole and the parasitic radiator is set at $g$. In this study,

Manuscript received February 16, 2012 ; Revised April 12, 2012 ; Accepted April 13, 2012. (ID No. 20120216-004J)

Dept. of Electronic Engineering, Kyonggi University, Suwon, Korea.

Corresponding Author : Young-Je Sung (e-mail : yjsung@kgu.ac.kr,)

This is an Open-Access article distributed under the terms of the Creative Commons Attribution Non-Commercial License (http://creativecommons.org/licenses/ by-nc/3.0) which permits unrestricted non-commercial use, distribution, and reproduction in any medium, provided the original work is properly cited. 


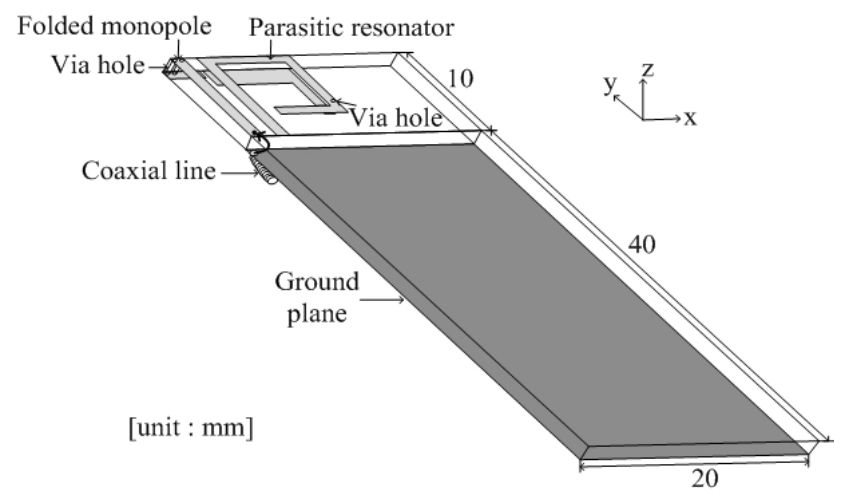

(a)

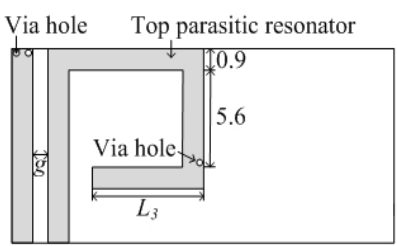

(b)

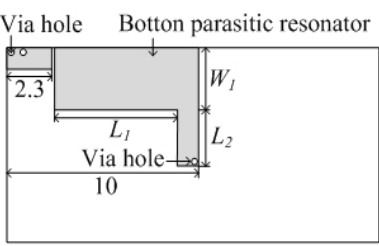

(c)
Fig. 1. (a) 3D structure, (b) top view, (c) bottom view.

the optimized antenna has the following design parameters: $L_{1}=6.6 \mathrm{~mm}, L_{2}=6.6 \mathrm{~mm}, L_{3}=3.4 \mathrm{~mm}, W_{1}=3 \mathrm{~mm}$ and $g=0.5 \mathrm{~mm}$. An Ansoft High Frequency Structure Simulator (HFSS V12) based on a finite element method FEM is used for the simulation.

\section{Simulated and Measured Results}

Fig. 2 shows the simulated and measured reflection coefficients of the proposed antenna. In this graph, the notation "without bottom parasitic resonator" indicates that the bottom parasitic resonator is removed from the proposed antenna and "without via" indicates that the via linking top and bottom parasitic resonators have been removed from the proposed antenna. Comparison of the

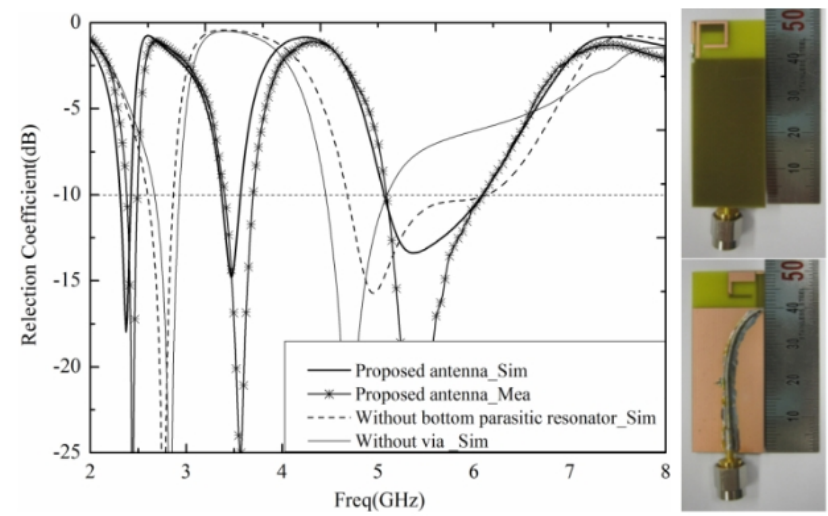

Fig. 2. Simulated and measured reflection coefficients of the proposed antenna.

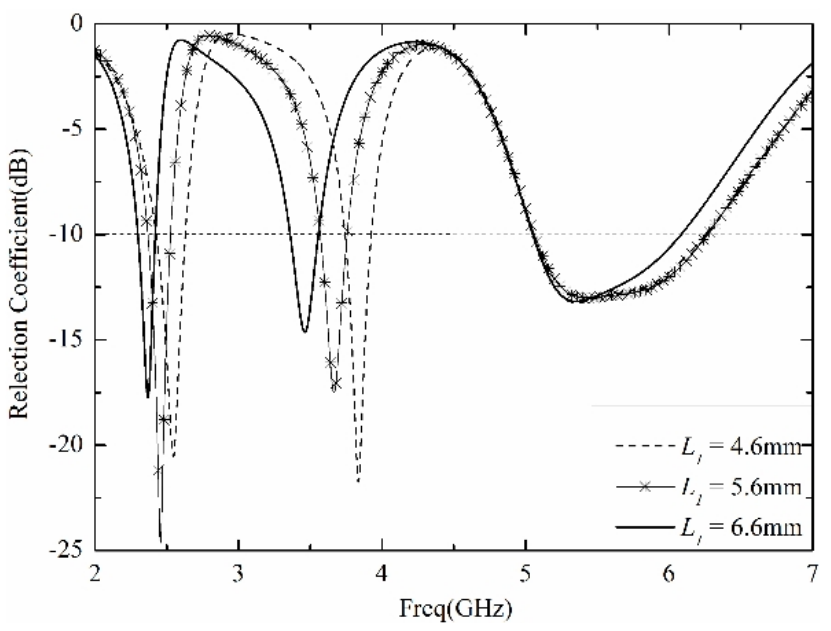

(a) Variation in lengths $L_{1}$

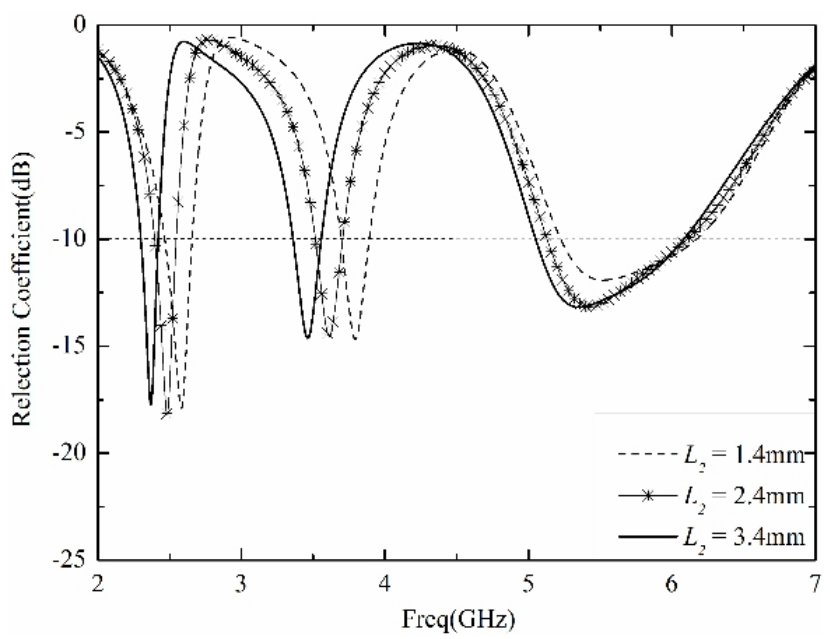

(b) Variation in lengths $L_{2}$

Fig. 3. Simulated reflection coefficients of the proposed antenna with different lengths $L_{1}$ and $L_{2}$.

reflection coefficients of these modified structures and the entire proposed antenna structure shows that $f_{2}$ is formed by the coupling capacitance and the via inductance between the top and bottom parasitic resonators. The comparison also shows that when $f_{1}$ decreases, $f_{3}$ increases by the bottom parasitic resonator. The measured results show that the antenna covers a $4.9 \%$ bandwidth $(2.38 \sim 2.5 \mathrm{GHz})$ at $f_{1}$, an $8.5 \%$ bandwidth $(3.4 \sim 3.7 \mathrm{GHz})$ at $f_{2}$, and a $17.86 \%$ bandwidth $(5.1 \sim$ $6.1 \mathrm{GHz})$ at $f_{3}$, thus allowing WLAN/WiMAX service.

Fig. 3 shows the simulation results of the reflection coefficient as a function of the different parasitic resonator lengths $L_{1}$ and $L_{2}$. The simulation results show that as $L_{1}$ and $L_{2}$ decrease, $f_{3}$ is only slightly influenced, whereas $f_{1}$ and $f_{2}$ increase. Fig. 4 shows the simulation results of the reflection coefficient as a function of the different parasitic resonator lengths $L_{3}$. As the simu- 


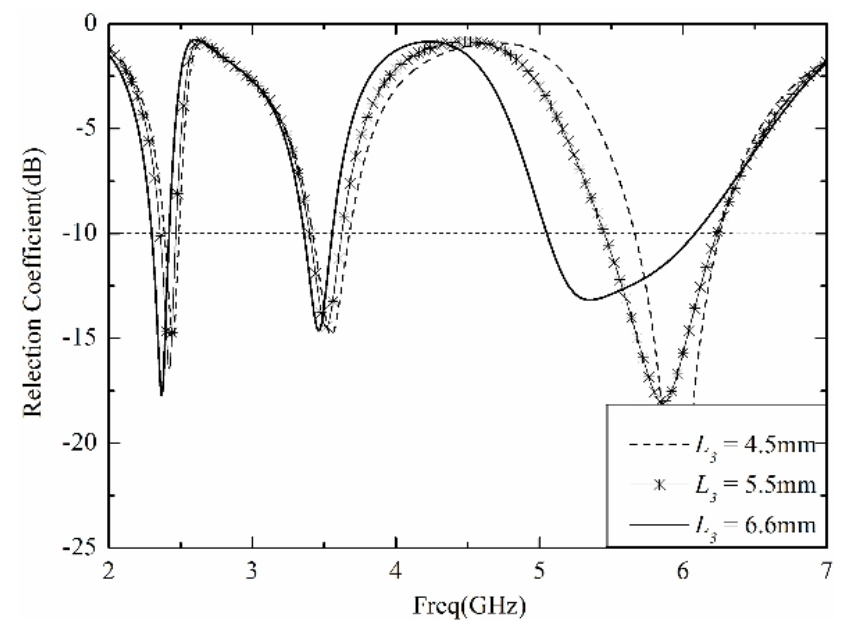

Fig. 4. Simulated reflection coefficients of the proposed antenna with different lengths $L_{3}$.

lation results show, a decrease in $L_{3}$ affects $f_{3}$ more than $f_{1}$ and $f_{2}$. However, $f_{1}$ and $f_{2}$ are hardly influenced when $L_{3}$ increases from $4.5 \mathrm{~mm}$ to $5.5 \mathrm{~mm}$ and $6.6 \mathrm{~mm}$. At this time, the impedance matching deteriorates but the bandwidth increases from $10.19 \%(5.68 \sim 6.29 \mathrm{GHz})$ to $18.67 \%(5.05 \sim 6.09 \mathrm{GHz})$.

Fig. 5 shows the measured $2 \mathrm{D}$ radiation patterns of the proposed antenna at $2.44 \mathrm{GHz}, 3.56 \mathrm{GHz}$, and 5.35 $\mathrm{GHz}$, respectively. The radiation patterns are measured in the $x y$ plane, the $x z$ plane, and the $y z$ plane. Omnidirectional radiation patterns are displayed in the azimuthal plane ( $x z$ plane) at $2.44 \mathrm{GHz}, 3.56 \mathrm{GHz}$, and $5.35 \mathrm{GHz}$. The $x y$ plane and $y z$ plane at $2.44 \mathrm{GHz}$ show that although the measured cross-pol is slightly higher than the simulated cross-pol, it has the same pattern as the monopole. Because the cross-pol supplements the co-pol well, the antenna has a completely omnidirectional radiation pattern. The measured maximum gains at $2.44 \mathrm{GHz}, 3.56 \mathrm{GHz}$, and $5.35 \mathrm{GHz}$ are $0.65 \mathrm{dBi}$, $1.82 \mathrm{dBi}$. and $3.1 \mathrm{dBi}$, respectively.

\section{Conclusion}

This paper presents a compact monopole antenna for wireless USB dongle applications. The monopole antenna is coupled to the parasitic radiator, which enables its double resonance $\left(f_{1}, f_{3}\right)$ to be easily obtained at 2.4 $\mathrm{GHz}$ and $5.5 \mathrm{GHz}$. In order to produce a third $3.5 \mathrm{GHz}$ band, a parasitic resonator is added to the bottom of the substrate and is connected to the parasitic resonator positioned on the top of the substrate through a via. In this manner, the proposed antenna covers the WiMAX $(3,400 \sim 3,600 \mathrm{MHz})$ and WLAN IEEE $802.11 \mathrm{a} / \mathrm{b} / \mathrm{g} / \mathrm{n}$ $(2,400 \sim 2,497 \mathrm{MHz}, 5,150 \sim 5,350 \mathrm{MHz}, 5,725 \sim 5,825$ $\mathrm{MHz}$ ) bands with a reflection level less than $-10 \mathrm{~dB}$.
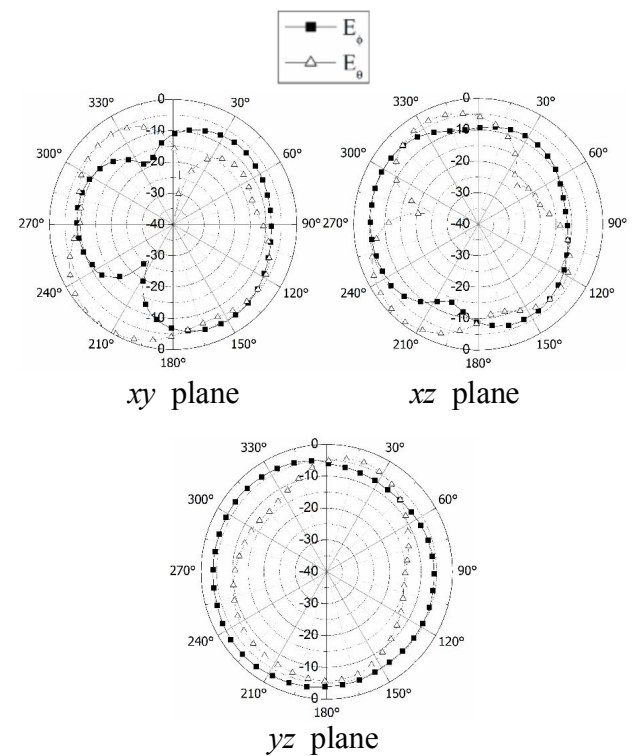

(a) $f_{1}=2.44 \mathrm{GHz}$
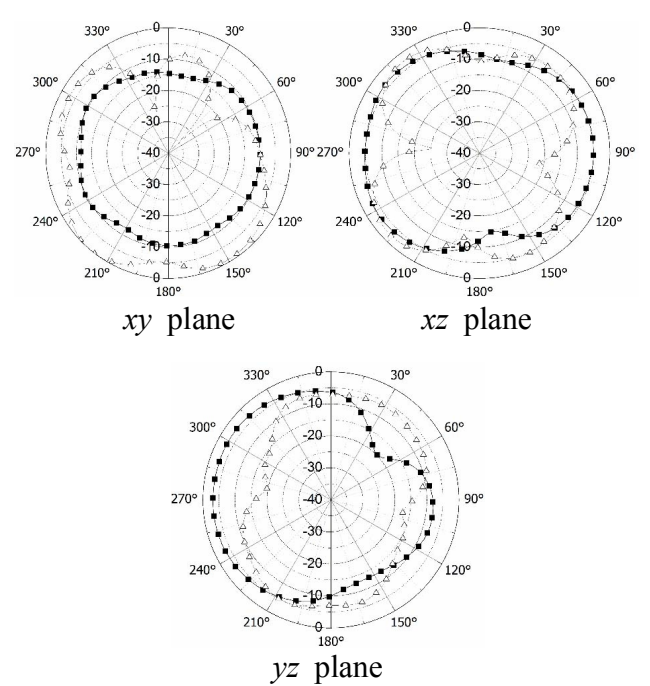

(b) $f_{2}=3.56 \mathrm{GHz}$
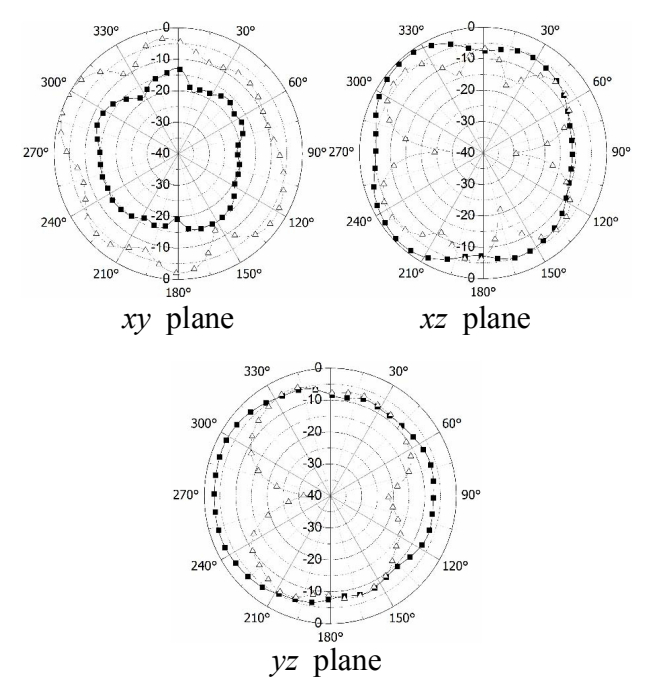

(c) $f_{3}=5.35 \mathrm{GHz}$

Fig. 5. Measured radiation patterns of the proposed antenna. 
The antenna occupies a $10 \mathrm{~mm} \times 10 \mathrm{~mm}$ area, and the total size of the substrate is $20 \mathrm{~mm} \times 50 \mathrm{~mm}$. Therefore, it is appropriate for compact wireless USB dongle applications.

This work was supported by Kyonggi University Research under Grant 2011.

\section{References}

[1] J. H. Lu, B. J. Huang, "Planar multi-band monopole antenna with L-shaped parasitic strip for WiMAX application," Electron. Lett., vol. 46, no. 10, pp. 671672, May 2010.
[2] S. Chaimool, K. L. Chung, "CPW-fed mirrored-L monopole antenna with distinct triple bands for WiFi and WiMAX applications," Electron. Lett., vol. 45, no. 18, pp. 928-929, Aug. 2009.

[3] A. R. Razali, M. E. Bialkowski, "Coplanar inverted-F antenna with open-end ground slots for multiband operation," IEEE Antennas Wireless Propag. Lett., vol. 8, pp. 1029-1032, Sep. 2009.

[4] K. G. Thomas, M. Sreenivasan, "Compact triple band antenna for WLAN/WiMAX applications," Electron. Lett., vol. 45, no. 16, pp. 811-813, Jul. 2009.

[5] S. H. Lee, Y. J. Sung, "Multiband antenna for wireless USB dongle applications," IEEE Antennas Wireless Propag. Lett., vol. 10, pp. 25-28, Jan. 2011. 